\title{
CARTOSSEMIÓTICA: uma abordagem peirciana dos mapas e da cartografia
}

\author{
Daniel Melo Ribeiro ${ }^{1}$
}

Resumo: O objetivo deste estudo é apresentar uma síntese da cartossemiótica - ramo da semiótica aplicada ao estudo dos mapas e da cartografia. Vamos enfatizar a cartossemiótica de origem peirciana, tomando como referência o trabalho de Winfried Nöth. Entendida como sinônimo de lógica, a semiótica de Peirce parte de categorias fenomenológicas primordiais para propor uma gramática que explica o funcionamento geral dos signos. Defendemos que a tríade signo, objeto e interpretante, proposta por Peirce, contempla os elementos fundamentais que envolvem o processo de representação e interpretação dos mapas. Neste estudo, os fundamentos da semiótica serão utilizados para esclarecer os seguintes aspectos da cartografia: (a) os mapas e seus dois objetos; (b) o mapa como representação; (c) o aspecto comunicacional dos mapas; (d) as propriedades icônicas, indiciais e simbólicas dos mapas; (e) o mapa como um diagrama.

Palavras-chave: semiótica, mapas, cartografia, Peirce.

\begin{abstract}
This study brings a synthesis of the cartosemiotics - a branch of semiotics applied to maps and cartography. Particularly, we emphasize the cartosemiotic inspired by Charles Peirce, taking as reference the work of Winfried Nöth. Understood as a synonym of logic, Peirce's semiotics starts from phenomenological categories to propose a grammar that explains the general behavior of signs. We argue that the triad sign, object and interpretant proposed by Peirce embraces the fundamental elements in the process of representation and interpretation of the maps. In this study, semiotics will be used to clarify the following aspects of cartography: (a) maps and their two objects; (b) the map as representation; (c) the communicational aspect of the maps; (d) the iconic, indexical and symbolic properties of the maps; (e) the map as a diagram.
\end{abstract}

Keywords: semiotics, maps, cartography, Peirce

\section{A semiótica dos mapas: um panorama metodológico}

A semiótica é uma doutrina que nos fornece as ferramentas lógicas para raciocinarmos sobre o comportamento dos signos. Podemos nos apoiar em seus princípios para compreender de que maneira criamos conhecimento a partir das representações do mundo exterior. Diante da pluralidade de signos que povoam o mundo sensível, interessa-nos abordar um tipo particular de signos visuais, voltados justamente às representações do espaço e do território: os mapas.

Mapas são signos capazes de representar propriedades espaciais de um território para um determinado leitor. Devido ao seu inegável poder comunicacional e à sua estreita sintonia com o desenvolvimento do raciocínio, os mapas há muito despertaram interesse dos 
estudiosos da semiótica. Segundo MacEachren (1995), a abordagem semiótica fornece os mecanismos conceituais para se explorar a maneira como os mapas produzem conhecimento:

\begin{abstract}
Os mapas são imbuídos de significado em virtude de suas relações semióticas (...) A semiótica fornece uma estrutura conceitual para desenvolver uma lógica de representação cartográfica que pode tirar proveito do que sabemos sobre representações cognitivas, categorias mentais e esquemas de conhecimento. (MACEACHREN, 1995, p. 213, 214)
\end{abstract}

Os estudos semióticos dos mapas estão agrupados em uma disciplina conhecida como cartossemiótica (NÖTH, 1998; LJUNGBERG, 2015). Trata-se de um ramo da semiótica aplicada que investiga as diferentes formas de representação cartográfica do espaço. Essa disciplina é influenciada por diferentes correntes metodológicas, cujas raízes se encontram em Peirce e em Saussure.

Um dos primeiros pesquisadores a desenvolver um estudo semiótico dos mapas foi Jacques Bertin (1973). Bertin procurou catalogar os elementos mínimos que constituem os signos cartográficos, a fim de compreender suas funções elementares para evitar polissemias e ambiguidades. Seu propósito era proporcionar uma taxonomia completa a ser aplicada no tratamento visual dos dados cartográficos (NÖTH, 1998). Segundo Ljungberg (2015), o sistema gráfico de variáveis desenvolvido por Bertin se tornou uma referência fundamental na transcrição cartográfica de informações geográficas. Outros autores também se destacam nos estudos de cartossemiótica, dentre eles Schlichtmann (2009) e Wolodtschenko (2011).

Mesmo sem citar explicitamente o termo cartossemiótica, alguns autores da cartografia crítica - ramo que investiga as implicações políticas dos mapas - também se inspiraram em teorias semióticas em suas análises. Por exemplo, Denis Wood (2010) baseouse nas considerações de Roland Barthes sobre signos e mitos para analisar um mapa rodoviário da Carolina do Norte. Wood utilizou o método semiológico desenvolvido por Barthes para desconstruir esse mapa - uma peça de propaganda promovida pelo governo daquele estado no final da década de 1970 - revelando intenções políticas por trás dos signos cartográficos ali empregados. Wood trabalha com uma perspectiva semiótica diádica do mapa como signo, partindo da identificação dos significantes (as marcações físicas) e dos significados. 
Pickles (2004) também faz referência ao trabalho de Barthes, ressaltando as propriedades denotativas e conotativas dos mapas. Pickles afirma que o mapa é um tipo de signo que mescla pelo menos três diferentes estruturas em sua construção: a estrutura gráfica, a estrutura matemática e a estrutura linguística. No entanto, esse autor enfatiza que o mapa pode ser entendido como um tipo de "texto" no seu sentido mais amplo: trata-se de uma construção que supostamente demandaria uma leitura direta e literal, mas que, como outros diversos textos, acaba por levantar problemas de interpretação e compreensão. Harley (2001) também trata dos mapas como um tipo de "texto". Segundo esse autor:

(...) mapas são textos no mesmo sentido que outros sistemas de signos não verbais pinturas, gravuras, teatro, filmes, televisão, música - são textos (...) Como livros, eles são também produtos tanto de mentes individuais e de valores culturais mais amplos de sociedades particulares (HARLEY, 2001, p. 36).

De maneira geral, notamos que os principais autores ligados à cartografia crítica (Harley, Wood e Pickles, por exemplo) foram influenciados pela corrente semiológica francesa. A proposta relativamente comum entre eles de "desconstruir os mapas" a fim de revelar as relações de poder da cartografia parte da ideia de que é necessário "quebrar" os elementos visuais dos mapas em pedaços menores, identificando suas interconexões. Nesse sentido, a semiótica cumpre um importante papel, na medida em que propõe uma ferramenta metodológica capaz de operar essa desconstrução. A influência da semiótica de origem linguística também se manifesta na opinião desses autores, que optam por ressaltar o caráter "textual" dos mapas.

Nöth (1998), por sua vez, aprofunda-se na abordagem triádica de Charles S. Peirce. Segundo tal abordagem, o mapa pode ser considerado como um signo composto de uma estrutura de três elementos interconectados: (1) o signo em si, (2) objeto e (3) interpretante. $\mathrm{O}$ signo (1) está habilitado a representar um objeto (2), causando um determinado efeito cognitivo (3) em um intérprete. Portanto, a cartossemiótica de origem peirciana irá tratar o mapa apresentado aos nossos sentidos como signo; o objeto a que ele se refere é o território e, por fim, o interpretante são as imagens mentais geradas a partir da leitura desse mapa. Tais imagens mentais se manifestam como outros signos, estimulando novas significações em cadeia, num processo conhecido como semiose. 
Segundo Nöth, a cartossemiótica desenvolve pesquisas enfatizando cada um desses três aspectos. Por exemplo, do ponto de vista do signo, os estudos dos mapas se concentram nas técnicas gráficas empregadas, no design cartográfico, nas cores, nas formas e nos padrões visuais. Do ponto de vista do objeto, os estudos se voltam para o território em si, podendo enfatizar desde técnicas de mensuração e coleta de dados georreferenciados, como também seus aspectos mais qualitativos. Por fim, os estudos dos interpretantes focalizam os efeitos cognitivos gerados pela leitura dos mapas.

Neste artigo, vamos enfatizar a semiótica desenvolvida por Charles Peirce. Entendemos que a tríade signo, objeto e interpretante contempla os elementos fundamentais que envolvem o processo de representação e interpretação dos mapas. Além disso, a cartossemiótica de origem peirciana também nos ajuda a esclarecer os seguintes conceitos, fundamentais para a análise semiótica de mapas: (a) os mapas e seus dois objetos; (b) o mapa como representação; (c) o aspecto comunicacional dos mapas; (d) as propriedades icônicas, indiciais e simbólicas dos mapas; (e) o mapa como um diagrama.

\section{Os mapas e seus dois objetos}

Diferentemente da abordagem diádica baseada nos conceitos de significante e significado (BARTHES, 2012), a lógica triádica reforça a relevância desempenhada pelo objeto do signo no processo de semiose. Segundo Jappy (2013, p. 14), “o objeto de Peirce é possivelmente o conceito mais excluído e mais estranho às teorias pós-estruturalistas e neoSaussurianas da contemporaneidade." O objeto cumpre um papel fundamental na semiose, uma vez que ele é o elemento que, indiretamente, determina o efeito interpretativo em uma mente, mediado pelo signo. Assim, por mais que o signo cartográfico seja tomado como o primeiro elemento da tríade, ele se refere a um território que ontologicamente o precede. Segundo o próprio Peirce:

Um signo tenta representar, em parte, pelo menos, um objeto que é, portanto, num certo sentido, a causa ou determinante do signo, mesmo que o signo represente o objeto falsamente. Mas dizer que ele representa seu objeto implica que ele afete uma mente de tal modo que, de certa maneira, determina, naquela mente, algo que é mediatamente devido ao seu objeto. Essa determinação da qual a causa imediata ou 
determinante é o signo e da qual a causa mediada é o objeto pode ser chamada de interpretante. $\left(\mathrm{CP}^{2}\right.$ 6.347)

Dessa maneira, entende-se que o objeto de um signo cartográfico é o território ao qual o mapa se refere. No entanto, Peirce expande essa noção e propõe dois objetos: o objeto dinâmico, que corresponde ao objeto em si, considerando toda a sua totalidade e complexidade; e o objeto imediato, que é a representação imperfeita e parcial do objeto que está contida dentro do signo. Por exemplo: o objeto dinâmico de um mapa da América do Sul seria o próprio continente em si, com suas inúmeras propriedades e qualidades (população, espaço físico, clima, vegetação, relações humanas, história, geografia etc.). A maneira como a América do Sul é particularmente representada em um mapa (formas, cores, tamanho, fronteiras, rótulos etc.) corresponde ao objeto imediato.

Essa divisão dos tipos de objeto é especialmente relevante no estudo dos mapas. Por exemplo, ainda que o objeto dinâmico seja o mesmo, há mapas que o representam de maneira totalmente distinta, ressaltando determinados aspectos. Nesse sentido, por estar contido no signo, o objeto imediato irá influenciar o modo pelo qual o mapa irá refletir determinado conhecimento pessoal e cultural de seu criador (LJUNGBERG, 2015). As diferentes maneiras de se representar um mesmo território se aplicam, por exemplo, nos estudos relacionados à Map Art (WOOD, 2010), uma vertente que trabalha os mapas e a cartografia no âmbito das artes plásticas. Artistas frequentemente subvertem a linguagem cartográfica com o objetivo de estimular interpretações alternativas sobre o espaço (RIBEIRO; CAPANEMA, 2016; CAQUARD et al., 2009).

Segundo Peirce:

Precisamos distinguir o Objeto Imediato - o objeto como está representado no signo - e o Real (não, porque o Objeto talvez seja completamente fictício, preciso escolher um termo diferente, portanto), digamos o Objeto Dinâmico, que, da natureza das coisas, o Signo não pode expressar, ele pode somente indicar e deixar o intérprete descobri-lo pela experiência colateral (EP2 $\left.2^{3} 498\right)$.

No trecho acima, Peirce apresenta as propriedades essenciais do objeto dinâmico. Em primeiro lugar, destacamos que a noção de objeto dinâmico se aproxima da ideia de ${ }^{2}$ A sigla CP corresponde aos Collected Papers de Peirce. O primeiro número indica o volume e os próximos números após o ponto indicam o parágrafo.

${ }^{3} \mathrm{~A}$ sigla EP corresponde à publicação Essential Peirce, editada por Nathan Houser. O número ao lado indica o volume. 
"realidade", enquanto que o objeto imediato seria o recorte dessa realidade que imediatamente se apresenta no signo. No entanto, Peirce também afirma que o objeto dinâmico pode ser de natureza fíctícia (e, por essa razão, ele optou por não chamá-lo de "objeto real” ou simplesmente "realidade").

Essa discussão sobre a natureza fictícia dos objetos é útil nos estudos dos mapas de territórios imaginários e dos mundos ficcionais. Resumidamente, trata-se das questões semióticas que envolvem o aparente paradoxo contido na representação de objetos que "não existem"; ou seja, objetos que foram criados a partir de uma determinada mente, mas que não encontram referentes existentes no mundo concreto (NÖTH, 2006), como os mapas de mundos da literatura de ficção (RIBEIRO, 2015) ou de mitos religiosos (RIBEIRO, 2016a).

Outro aspecto relevante diz respeito à possibilidade de um signo representar o objeto falsamente. Ou seja, Peirce não descarta a possibilidade de que os signos também mentem. Essa propriedade dos signos nos permite levar em conta o fato de que os mapas não necessariamente são representações corretas e precisas da realidade espacial. Embora a cartografia científica cubra o mapa de uma autoridade discursiva, a "verdade" contida em um mapa, portanto, pode ser abertamente questionada.

\section{O mapa como representação}

A ideia do mapa como representação encontra uma certa rejeição por parte de alguns autores na cartografia, especialmente em contextos onde se pretende reforçar a natureza parcial e política dos mapas. Essa aparente rejeição refere-se à ideia de que o conceito de representação seria insuficiente, pois reforçaria a interpretação de que o mapa é uma cópia fiel da realidade, o que inibiria seus aspectos contingenciais e políticos. No entanto, sob o ponto de vista semiótico, a noção de que o signo cartográfico representa um objeto não exclui o fato de que essa representação pode conter distorções ou imperfeições. Vejamos como isso pode ocorrer.

O trabalho de MacEachren (1995) em How maps work também é amplamente sustentado pela lógica triádica proposta por Charles Peirce ${ }^{4}$. MacEachren se aprofunda em

\footnotetext{
${ }^{4}$ No entanto, esse autor opta por derivar sua teoria semiótica aplicada aos mapas a partir das considerações de C. Morris. MacEachren apoia-se nas três dimensões de semiose sugeridas por Morris: a dimensão semântica, a 
teorias cognitivas e de modelos representacionais de conhecimento para tratar dos processos de significação envolvidos na cartografia. Seu principal argumento consiste em defender a natureza representacional dos mapas, uma propriedade que é frequentemente ignorada ou interpretada de maneira superficial.

\begin{abstract}
Explorar os mapas como uma representação constrói importantes conexões entre a cartografia e uma variedade de campos relacionados com esse tópico em suas várias facetas, incluindo sistemas de informação geográfica (GIS) e sensoriamento remoto, bem como as artes, a ciência cognitiva, a sociologia, a psicologia cognitiva e ambiental, a semiótica e mesmo a história e a filosofia da ciência (MACEACHREN, 1995, p. 1).
\end{abstract}

Nesse aspecto, MacEachren diverge dos argumentos levantados pelos autores da cartografia crítica, que preferem adotar uma certa distância desse conceito. Fala-se, por exemplo, em "imagens refratadas" (HARLEY, 2001, p. 53), "sistemas de proposições" (WOOD, 2010, p. 34), cartografia "processual” (KITCHIN; DODGE, 2007, p. 13) ou mesmo em "crise de representação" (PICKLES, 2004, p. 28). Crampton (2010) afirma que a palavra "representação":

...implica algo que existe anteriormente ao ato de se mapear (o espaço ou a paisagem a ser mapeada). Há uma paisagem lá fora, e ela é capturada de uma maneira "representativa" em um mapa (...) A paisagem se apresenta primeiro, e tal como uma pintura ou uma fotografia, tomamos os elementos essenciais dela para nossa representação (...) A cartografia crítica, por outro lado, argumenta que o mapeamento cria um conhecimento e um significado espacial específicos, identificando, nomeando, categorizando, excluindo e ordenando (...) O mapeamento cria conhecimento tanto quanto (e para alguns 'ao invés de') o reflete (CRAMPTON, 2010, p. 45, 46).

Kitchin e Dodge (2007, p. 12) afirmam que a "pesquisa cartográfica se reorienta como uma ciência de práticas, não de representações”. Denis Wood, por sua vez, é ainda mais incisivo:

A maneira mais fácil de libertarmos o poder dos mapas seria perceber o fato de que mapas são proposições. Tão logo concebemos os mapas como representações, nossa imaginação será amarrada a uma imagem alegada de que os mapas não são mais do

dimensão pragmática e a dimensão sintática. De maneira controversa, MacEachren também sugere que não somente o signo pode atuar como elemento mediador entre os outros dois elementos da semiose. Tanto o objeto quanto o interpretante também poderiam ser considerados como mediadores (MACEACHREN, 1995, p. 220). 
que espelhos. Invariavelmente, essa imagem recebida é inadequada, imprecisa, frequentemente falsa: e sempre é escrava de interesses dominantes (WOOD, 2010, p. 39, grifo do autor).

De fato, ao reforçar os aspectos políticos, a cartografia crítica procura enfatizar que os mapas vão além da mera representação especular da realidade. No entanto, a noção de representação aqui defendida não se restringe ao mero processo de reflexão passiva e se aproxima bastante da noção de semiose: "os mapas são representações espaciais que podem estimular outras representações, num ato de construção de conhecimento" (MACEACHREN, 1995, p. VII).

De acordo com a lógica triádica da semiótica de Peirce, os processos de representação que se constroem em torno de um signo constituem uma das faces dessa tríade: a saber, a relação entre o signo e o objeto. Ou seja, o signo representa o objeto. Por outro lado, há também uma relação de interpretação que ocorre na relação entre o signo e o interpretante, na outra "perna" da tríade. Ou seja, ao mesmo tempo em que o signo representa seu objeto, ele também está apto a gerar uma interpretação em uma determinada mente (figura 1).

Figura 1: representação e interpretação em um signo

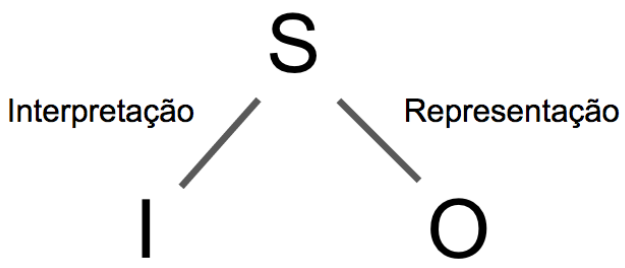

Fonte: próprio autor

Assim, entendemos a representação como a relação que se estabelece entre o signo e seu objeto, ou seja, entre o mapa e o território. Segundo Peirce (CP 2.273) representar é "estar no lugar de, isto é, estar numa tal relação com um outro que, para certos propósitos, é considerado por alguma mente como se fosse esse outro." Nesse sentido, representar significa colocar-se no lugar de um outro. Assim, o signo representa o objeto, causando um certo efeito interpretativo em uma mente. O efeito interpretativo é mediado pela ação do signo: em outras 
palavras, a interpretação criada sobre um território em uma mente passa pela mediação do signo cartográfico.

Porém, um dos princípios fundamentais dessa relação é que o signo é incapaz de representar o objeto em sua totalidade. O signo é sempre uma representação parcial e nunca será capaz de contemplar toda a complexidade que constitui um objeto. Daí a explicação semiótica de que $o$ mapa não é o território. Em resumo, entendemos que, ao representar um território, o mapa não necessariamente reproduz uma visão especular daquele espaço: haverá sempre uma espécie de parcialidade ou - como preferem os pesquisadores da cartografia crítica - uma distorção. Nesse sentido, o nosso entendimento do conceito de representação não contradiz a ideia de que um mapa é uma proposição parcial da realidade. Trata-se de uma propriedade semiótica elementar de todo signo.

\section{4. $O$ aspecto comunicacional dos mapas}

Outro aspecto que merece esclarecimento é associar as propriedades comunicativas de um mapa a um modelo linear do tipo emissor - canal - receptor. Segundo Pickles (2004, p. 33), essa noção funcional da cartografia sofreu uma grande influência do modelo comunicacional proposto pela teoria matemática da informação de Shannon e Weaver. Sob esse ponto de vista, predominante nas décadas de 1960 e 1970, o mapa era entendido como uma ferramenta utilizada para transmitir informações espaciais, baseada num fluxo unidirecional. O cartógrafo, no papel do emissor, seria responsável por codificar os dados puros e brutos da realidade em um mapa, que por sua vez seriam decodificados por um leitor ideal, capaz de interpretar os símbolos de maneira atenta e adequada. O nível de eficiência comunicacional do mapa estaria, portanto, relacionado à quantidade e à precisão da informação transmitida.

Segundo MacEachren (1995), esse modelo pressupõe que os mapas possuem um propósito inquestionável e seu objetivo é comunicar o conteúdo selecionado para atingir esse propósito com eficiência. O cartógrafo teria acesso a um determinado conhecimento que seria traduzido e disseminado através do mapa, ao invés de ser construído e analisado pelo leitor, na outra extremidade do fluxo. "A comunicação passou a ser vista como uma função primária da cartografia e o mapa foi considerado o veículo dessa comunicação" (MACEACHREN, 
1995, p. 4). Além disso, a própria cartografia se tornou "um processo de comunicação de informações espaciais que possui inputs, transmissão e recepção de informação, e portanto poderia ser analisado como um sistema" (MACEACHREN, 1995, p. 4). Esse modelo sistêmico induz a interpretação de que seria possível aprimorar a comunicação dos mapas reduzindo a perda de informação nos vários pontos desse sistema. Além disso, os leitores dos mapas seriam entidades básicas, que simplesmente respondem aos inputs fornecidos no início do fluxo.

No entanto, a semiótica questiona a premissa de que os mapas são exclusivamente interpretações objetivas da realidade. De acordo com MacEachren, "uma das principais falhas identificadas no paradigma do modelo comunicacional da cartografia foi o fracasso em contar com o papel ativo do usuário em derivar significado dos mapas.” (MACEACHREN, 1995, p. 23). Por estar intimamente relacionada com as teorias sobre cognição e percepção visual, a semiótica contribui para a compreensão da maneira como extraímos significado dos mapas, expandindo a noção simplificada de comunicação baseada em um sistema linear. Para desenvolver esse argumento, MacEachren se apoia em um modelo cognitivo baseado em esquemas mentais de conhecimento. Os esquemas mentais são responsáveis por realizar uma mediação entre o interpretante gerado pelo mapa e o conhecimento prévio do leitor. Em outras palavras, o leitor se interroga sobre a informação visual contida no mapa, comparando seu conhecimento prévio com esse esquema mental elaborado por ele mesmo. O significado derivado pode resultar na modificação desse esquema ou mesmo estimular a criação de um novo esquema.

Nas palavras de MacEachren, esse modelo definitivamente afasta a hipótese de que o processo de significação dos mapas ocorre por um modelo de transmissão unidirecional de informação, "e sim em um sistema modular onde a informação é criada e recriada por uma série de processos interpretativos" (MACEACHREN, 1995, p. 49). Em outros termos, a significação ocorre por meio da geração de uma cadeia sucessiva de novos interpretantes, num processo de semiose. Portanto, essa abordagem semiótica reforça a noção de que o mapa não é um mero veículo de transmissão de informações. O leitor possui um papel ativo na construção desses significados, na medida em que ele combina as informações do mapa com seu conhecimento prévio para produzir conclusões que não necessariamente correspondem às intenções iniciais do cartógrafo (MACEACHREN, 1995, p. 9). 
Em resumo, quando nos referimos aos aspectos comunicacionais dos mapas, consideramos duas propriedades semióticas fundamentais: por um lado, o fato de que o mapa, por ser um signo, encarna uma mensagem em potencial. Nesse sentido, o mapa é um signo material, concreto. Ao representar um território, o signo se apresenta em seu lugar, carregando um conjunto de propriedades visuais que pode dizer algo sobre seu objeto. Para haver comunicação, portanto, deve haver um signo. Por outro lado, o mapa também é capaz de afetar uma determinada mente, provocando um efeito interpretativo. No entanto, esse efeito interpretativo não necessariamente corresponde ao propósito inicial do cartógrafo: ele é elaborado por um processo cognitivo na mente do intérprete, que usa sua experiência colateral (seu conhecimento prévio) para criar um significado a partir do signo cartográfico. Sua interpretação pode se transformar em um outro signo, despertando uma cadeia de significação chamada de semiose.

\begin{abstract}
Que a semiótica é também uma teoria da comunicação está implícito, em primeiro lugar, no fato de que não há comunicação sem signos. Em segundo lugar, está implícito no fato de que a semiose é, antes de tudo, um processo de interpretação, pois a ação do signo é a ação de ser interpretado em um outro signo. Por isso mesmo, o significado de um signo é um outro signo e assim por diante, processo através do qual a semiose está em permanente devir. Como poderia haver comunicação se não houvesse produção de signos para serem interpretados? (SANTAELLA e NÖTH, 2004, p. 160-161).
\end{abstract}

\title{
5. As propriedades icônicas, indiciais e simbólicas dos mapas
}

Como já é do conhecimento da comunidade de pesquisadores da semiótica, Peirce criou uma extensa e detalhada classificação de signos. Muito mais do que meramente sugerir rótulos, Peirce buscou compreender, em profundidade, como os signos poderiam se comportar. Nesse sentido, a teoria geral dos signos de Peirce se apresenta como uma poderosa ferramenta lógica de identificação das propriedades gerais dos signos e, por consequência, do próprio pensamento (SANTAELLA, 1995).

Peirce conduziu a sua noção de signo a um patamar extremamente abstrato, a ponto de considerar que qualquer coisa do mundo sensível poderia atuar como um signo. Dessa maneira, Peirce ampliou o campo de atuação de sua doutrina lógica (ou semiótica), que tem a 
pretensão de ser uma verdadeira filosofia do pensamento, ou seja, uma ciência que trata das regras formais do raciocínio.

Assim, Peirce não buscava delimitar um significado específico para os signos (no sentido de que "A" significa "B", ou, em termos cartográficos, que "verde" significa "vegetação" ou que "linhas escuras contínuas" significam "estradas"). De maneira geral, sua maior preocupação era saber como o conhecimento científico é adquirido e de que maneira poderíamos provar que esse conhecimento é válido, contribuindo para o avanço da razoabilidade no longo curso do tempo. De acordo com Jappy (2013, p. 27):

Na classificação triádica dos signos criada em 1903, Peirce não estava interessado em determinar o significado de um determinado signo, o que seria de interesse muito pessoal e individual; mas sim em investigar os três aspectos gerais de um signo e de sua ação, ou seja, os aspectos dos signos que são universalmente válidos e nos habilitam a classificá-los.

Foge ao escopo deste artigo se aprofundar nas categorias fenomenológicas de Peirce 5 . Tampouco detalharemos as diversas possibilidades de classificação dos tipos de signo ${ }^{6}$. No entanto, vamos trazer uma breve explicação sobre como os signos podem ser classificados, tendo como base as categorias fenomenológicas da primeiridade, secundidade e terceiridade. Em seguida, mencionaremos uma das tricotomias classificatórias da semiótica: as propriedades icônicas, indiciais e simbólicas.

A classificação desenvolvida por Peirce, bem como todo o seu edifício filosófico, encontram fundamento na sua original concepção de categorias universais triádicas e recursivas, conhecidas como (1) primeiridade, (2) secundidade e (3) terceiridade. Base para a compreensão da fenomenologia e da semiótica, as categorias permitem identificar, respectivamente, as propriedades dos signos relacionadas tanto às suas (1) qualidades e possibilidades, (2) singularidades e afirmações, bem como suas (3) generalidades e regularidades.

De acordo com Peirce, a semiótica é incapaz de adotar premissas arbitrárias de maneira independente, ou seja, ela requer a prévia consideração dos fenômenos externos ao pensamento. Tais fenômenos se apresentam a determinadas mentes (não restritas ao aparelho cognitivo humano) de acordo com a predominância de cada uma das categorias

\footnotetext{
${ }^{5}$ Cf. Santaella (2005) e Ibri (2015)

${ }^{6}$ Cf. CP 2.227-273, Santaella (1995).
} 
fenomenológicas mencionadas. Nesse sentido, a semiótica possui um caráter ontológico que parte dos estímulos fornecidos pelo mundo exterior com o objetivo de desvendar como os signos se comportam. Portanto, cabe à semiótica fornecer o aparato metodológico para desvendar como opera o pensamento, amparada por uma primeira apuração dos fenômenos, cujos princípios estão sob o domínio da fenomenologia. Por consequência, os diversos tipos de signos possuem direta correspondência com as três categorias, que se manifestam em distintos graus de intensidade, dependendo da ação desempenhada pelo signo.

O comportamento dos signos pode ser classificado a partir da análise dos elementos fundamentais que compõem sua tríade (signo, objeto e interpretante), bem como da forma como eles se relacionam. As três classificações básicas (chamadas tricotomias) consideram o signo em si mesmo (S), a relação do signo com o seu objeto (S-O) e a relação do signo com o interpretante (S-I). Quando consideramos somente a relação do signo com o seu objeto ${ }^{7}$, os signos podem ser classificados como icones, índices ou símbolos.

Um ícone é um signo que, na relação com seu objeto, compartilha algum tipo de semelhança com ele. Em outras palavras, um ícone apresenta qualidades (formas, aparência, cor, sons, aspecto, tonalidade, estrutura interna etc.) que se assemelham ao objeto que ele representa. Um desenho de uma casa ou uma pintura de um rosto são exemplos de ícones, uma vez que suas formas visuais possuem semelhanças com o objeto. Nesse sentido, o ícone é um signo através do qual se manifesta, de maneira predominante, a categoria da primeiridade (qualidades e possibilidades).

Por sua vez, um índice é um signo que possui uma conexão direta com seu objeto, sendo afetado por ele. Em outras palavras, um índice denota a existência de um objeto e traz alguma afirmação sobre suas propriedades. Uma pegada na areia ou um termômetro são exemplos de índices que apontam para a existência de seus objetos (no caso, a passagem de um animal por aquele local ou a condição da temperatura de uma região). Nesse sentido, o índice é um signo através do qual se manifesta, de maneira predominante, a categoria da secundidade (singularidades e afirmações).

Por fim, um símbolo é um signo que se refere ao seu objeto pela virtude de uma lei ou um hábito. Em outras palavras, o símbolo é criado em função de uma regra que irá, por convenção, determinar seu comportamento. Uma letra qualquer do alfabeto ou o nome de uma

\footnotetext{
${ }^{7}$ Nesse caso, consideramos o objeto dinâmico.
} 
praça são exemplos de símbolos, uma vez que seu significado resulta de uma convenção ou regra estabelecida previamente. Os símbolos estão predominantemente regidos pela categoria da terceiridade (generalidades e regularidades).

No entanto, as classificações de ícone, índice e símbolo não devem ser entendidas de maneira excludente. Tal como nas as categorias fenomenológicas, as classificações são recursivas (a categoria 1 está contida na 2, que por sua vez está contida na 3). Ou seja, um índice também apresenta propriedades icônicas. De maneira análoga, um símbolo também apresenta propriedades indiciais e, por consequência, icônicas. Isso significa, por exemplo, que uma placa de trânsito do tipo "PARE" pode apresentar, ao mesmo tempo, propriedades simbólicas (por ser uma convenção), indiciais (por afirmar algo sobre aquele lugar específico) e icônicas (por trazer a cor vermelha).

Após essa explicação, podemos voltar ao tema principal, lançando a seguinte pergunta: como as propriedades icônicas, indiciais e simbólicas se manifestam nos mapas? Em primeiro lugar, mapas possuem características fortemente icônicas. Tais características se manifestam, por exemplo, nas formas dos continentes, na representação do curso de um rio, na sinuosidade de uma rodovia, ou mesmo nas cores usadas para representar florestas, formações rochosas, mares e oceanos. Tais qualidades possuem semelhanças com o território representado, sejam elas físicas ou estruturais. As propriedades icônicas dos mapas são fundamentais para que o leitor possa estabelecer analogias com o mundo para o qual ele aponta.

Por outro lado, mapas também apresentam um forte apelo indicial. Ao posicionar uma cidade, uma fronteira ou uma formação geográfica num determinado local, o mapa explicitamente indica, aponta e denota sua existência. Nesse sentido, o mapa funciona como um poderoso índice, afirmando que ali se encontra algo específico que merece ser comunicado. Trata-se de uma propriedade essencial, pois é sobre esses índices que navegantes, viajantes ou estudiosos se apoiam para buscar orientação: se o mapa diz que "ali há uma ilha", então é razoável acreditar que ela exista. O aspecto indicial dos mapas reforça sua autoridade como um signo de afirmação de fatos que dizem respeito ao espaço (mas, ao mesmo tempo, devemos nos lembrar que os signos também podem mentir, ou mesmo representar o objeto de maneira parcial). Por isso a cartografia científica se interessa bastante 
pelos índices: um mapa deve ser preciso, comunicando claramente um determinado fato geográfico.

Por fim, mapas também apresentam propriedades simbólicas. Grande parte da gramática cartográfica depende de convenções que foram estabelecidas ao longo da história. São exemplos de convenções da cartografia: o hábito de se representar o norte na parte superior do mapa; as regras que definem o posicionamento dos meridianos; as legendas que auxiliam o entendimento dos códigos aplicados no mapa; as regras matemáticas de projeção responsáveis por "traduzir" a forma esférica do globo em um plano retangular, e assim por diante. Portanto, a cartografia científica tem interesse direto no controle e definição dessas convenções simbólicas dos mapas, uma vez que ela busca estabelecer padrões e hábitos que possam assegurar uma leitura "correta" dos mapas.

O questionamento dos aspectos simbólicos dos mapas é uma das estratégias adotadas pelos artistas para subverter a leitura tradicional que fazemos sobre o espaço. Além disso, por se tratarem de convenções que invariavelmente reforçam relações de poder, os aspectos simbólicos dos mapas foram duramente atacados pelos pensadores da cartografia crítica. As convenções cartográficas reforçam que os mapas são signos culturais, inseridos em um contexto que exerce uma enorme influência sobre suas regras de representação. Expor a origem e as razões dessas convenções, portanto, permite uma interpretação mais crítica sobre a natureza dos mapas.

\section{O mapa como um diagrama}

Por apresentarem características icônicas, os mapas possuem semelhanças com o território que representam. Porém, tais semelhanças não se restringem a semelhanças físicas (cores, formas e texturas, por exemplo). Os mapas também podem apresentar analogias estruturais com o objeto representado. Quando um ícone compartilha semelhanças com a maneira como seus elementos internos estão logicamente organizados, ele pode ser classificado como um diagrama. São exemplos de diagrama: uma equação matemática, um gráfico de barras, um manual de instruções, um fluxograma. Em tais diagramas, não há necessariamente uma semelhança física com o objeto representado, e sim uma tradução visual 
de formas que apresentam fortes relações com sua estrutura lógica interna. Dessa maneira, os diagramas se tornam poderosos instrumentos de raciocínio, que não somente estimulam a descoberta de novas relações ocultas no objeto, mas também facilitam a elaboração de inferências lógicas sobre ele. Daí o uso extensivo de diagramas em diversas ciências, seja na matemática, na física ou na química, por exemplo (STJERNFELT, 2013).

Uma maneira simples de percebemos tais propriedades aplicadas à cartografia pode ser identificada nos mapas de metrô. As distâncias entre estações, a escala do mapa e o formato dos túneis, por exemplo, não necessariamente possuem semelhanças físicas com a realidade. Para a finalidade do passageiro desse tipo de transporte, basta compreender as relações lógicas necessárias ao seu deslocamento pelas estações. Tal tipo de estratégia semiótica acaba por se tornar eficiente, na medida em que elimina elementos desnecessários do mapa naquele contexto de uso. O desenvolvimento mais aprofundado das propriedades diagramáticas dos mapas pode ser encontrado em Ribeiro (2016b).

\section{Considerações finais}

De maneira introdutória, este estudo procurou ressaltar algumas propriedades semióticas essenciais dos mapas, tendo como referência o método desenvolvido por Charles Peirce. Além disso, procuramos também apresentar algumas referências dos estudos semióticos dos mapas que se fundamentam em outras correntes teóricas. Em resumo, acreditamos que a cartossemiótica pode oferecer importantes subsídios conceituais para a análise de mapas em contextos que extrapolam até mesmo a cartografia científica tradicional. O potencial comunicativo dos mapas é inegável, o que torna a cartossemiótica uma disciplina particularmente relevante para compreender como funcionam tais tipos de signos.

\section{Referências}

BARTHES, Roland. Elementos de semiologia. São Paulo: Cultrix, 2012.

BERTIN, Jaques. Sémiologie graphique: Les diagrammes-Les réseaux-Les cartes. Paris: Gauthier-VillarsMouton \& Cie, 1973. 
CAQUARD, Sébastien; PIATTI, Barbara; CARTWRIGHT, William. Editorial: Special Issue on Art \& Cartography. The Cartographic Journal: Art \& Cartography Special Issue, v. 46, n. 4, p. 289-291, 2009.

CRAMPTON, Jeremy. Mapping: a Critical introduction to cartography and GIS. Critical Introductions to Geography. Chichester, UK: Willey-Blackwell, 2010.

HARLEY, J. B. The new nature of maps: essays in the History of Cartography. Baltimore: The Johns Hopkins University Press, 2001.

IBRI, Ivo. Kósmos Noetós: a arquitetura metafísica de Charles S. Peirce. São Paulo: Paulus, 2015.

JAPPY, Tony. Introduction to peircean visual semiotics. London: Bloomsbury, 2013.

KITCHIN, Rob; DODGE, Martin. Rethinking maps. Progress in Human Geography. Vol. 31, n. 3. 2007. p. 1-14. DOI: 10.1177/0309132507077082.

LJUNGBERG, Christina. Cartosemiotics. In: TRIFONAS, Peter Pericles (org.). International handbook of semiotics. London: Springer, 2015. p. 759-769. Disponível em $<$ https://link.springer.com/book/10.1007/978-94-017-9404-6/page/2>. Acesso em: $14 / 03 / 2017$.

MACEACHREN, Alan M. How maps work: representation, visualization, and design. New York: The Guilford Press, 1995.

NÖTH, Winfried. Cartossemiótica. In: OLIVEIRA, Ana Claudia; FECHINE, Yvana. Visualidade, urbanidade, intertextualidade. São Paulo: Hacker, 1998.

NÖTH, Winfried. Representations of Imaginary, Nonexistent, or Nonfigurative Objects. Cognitio, São Paulo, v. 7, n. 2, p. 277-291, jul/dez. 2006.

PEIRCE, C. S. Collected Papers, v. 1-6, Hartshorne and Weiss (eds.); v. 7-8, Burks. (ed.). Cambridge, Mass.: Harvard University Press. 1931-1958.

PEIRCE, C. S. The essential Peirce: Selected philosophical writings. HOUSER, N. (ed.). Vol. 2. Indiana University Press, 1998.

PICKLES, John. A history of spaces: cartographic reason, mapping and the geo-coded world. New York: Routledge, 2004.

RIBEIRO, D. M.. Cartografia Literária: uma abordagem cartossemiótica sobre a Guerra dos Tronos. In: V Congresso Internacional de Comunicação e Cultura - ComCult, 2015, Sao Paulo. Anais do V Congresso Internacional de Comunicação e Cultura. São Paulo: Faculdade Cásper Líbero, 2015. Disponível em: < 
http://www.cisc.org.br/portal/jdownloads/comcult/daniel_melo_ribeiro.pdf $>$. Acesso em: 08/08/2017.

RIBEIRO, D. M.. Utopia e Territórios Imaginários: Representações Cartográficas do Espaço Medieval. In: XXXIX Congresso Brasileiro de Ciências da Comunicação - INTERCOM 39, 2016a, São Paulo. Anais do XXXIX Congresso Brasileiro de Ciências da Comunicação.

São Paulo: Intercom, 2016. Disponível em: <
http://portalintercom.org.br/anais/nacional2016/resumos/R11-1255-1.pdf >. Acesso em: 08/08/2017.

RIBEIRO, D. M.. Capacidades heurísticas dos mapas segundo a semiótica de Charles Peirce. In: 16a. Jornada de Estudos Peircianos, 2016, São Paulo. Caderno da 16a. Jornada de Estudos Peircianos, 2016b. v. 16. p. 163-181.

RIBEIRO, D. M.; CAPANEMA, L. Limiares e Fronteiras na Arte: um estudo sobre a experiência estética em Walter Benjamin. Interin (UTP), v. 21, p. 05-22, 2016. Disponível em $<$ http://seer.utp.br/index.php/i/article/view/462>. Acesso em: 03/05/2017.

SANTAELLA, Lucia. Teoria geral dos signos: semiose e autogeração. São Paulo: Ed. Pioneira, 1995.

SANTAELlA, Lucia. Matrizes da Linguagem e Pensamento: Sonora Visual Verbal. São Paulo: Iluminuras, 2005.

SANTAELlA, Lucia; NÖTH, Winfried. Comunicação e semiótica. São Paulo: Hacker Editores, 2004.

SCHLICHTMANN, Hansgeorg. Overview of the semiotics of the maps. In: Proceedings, 24th International Cartographic Conference, Santiago, Chile, 15-21. 2009.

STJERNFELT, Frederik. Diagramas: foco para uma epistemologia peirceana. In: QUEIROZ, J.; MORAES, L. (orgs.) A lógica de diagramas de Charles Sanders Peirce: implicações em ciência cognitiva, lógica e semiótica. Juiz de Fora: Editora UFJF, 2013.

WOLODTSCHENKO, Alexander. Quo vadis classic cartosemiotics \& quo vadis theoretical cartography? Journal for Theoretical Cartography. ISSN, v. 1868, p. 1387, 2011.

WOOD, Denis. Rethinking the power of maps. New York: The Guilford Press, 2010. 